\title{
Neuroendocrine aspects of pediatric aggression: Can hormone measures be clinically useful?
}

This article was published in the following Dove Press journal:

Neuropsychiatric Disease and Treatment

7 October 2010

Number of times this article has been viewed

\author{
Drew H Barzman' \\ Avni Patel ${ }^{2}$ \\ Loretta Sonnier' \\ Jeffrey R Strawn ${ }^{3}$ \\ 'Division of Child and Adolescent \\ Psychiatry, Cincinnati Children's \\ Hospital Medical Center, Cincinnati, \\ OH, USA; ${ }^{2}$ Miami University, Oxford, \\ $\mathrm{OH}$, USA; ${ }^{3}$ Department of Psychiatry, \\ University of Cincinnati, College of \\ Medicine, Cincinnati, OH, USA
}

Correspondence: Drew H Barzman MLC 30I4, 3333 Burnett Ave, Cincinnati, $\mathrm{OH}$ 45229-3039, USA

$\mathrm{Tel}+$ I 5136368727

Fax + I 5136364283

Email drew.barzman@cchmc.org

\begin{abstract}
Pediatric aggression is common in human societies, mainly presenting as impulsive aggression or predatory aggression. Numerous psychiatric disorders can contain aggression as a symptom, leading to difficulties in diagnosis and treatment. This review focuses on the biological systems that affect pediatric aggression. We review the hypothalamic-pituitary-adrenal (HPA) axis, the hypothalamic-pituitary-gonadal (HPG) axis, and the mechanisms by which these axes influence the body and mind of aggressive children and adolescents. Although this review focuses on the HPA and HPG axes, it is important to note that other biological systems have relationships with these two axes. Based on the results of the studies reviewed, elevated cortisol concentrations were associated with impulsive aggression, whereas, low levels of cortisol were associated with callous-unemotional traits similar to predatory aggression. Higher levels of dehydroepiandrosterone were correlated with higher levels of aggression as were higher levels of testosterone. However, there have been discrepancies in the results between various studies, indicating the need for more research on hormonal levels and pediatric aggression. In the future, hormonal levels may be useful in determining what treatments will work best for certain pediatric patients.
\end{abstract}

Keywords: youth, cortisol, adrenocorticotropin-releasing hormone, corticotropin-releasing hormone, HPA axis, HPG axis

\section{Introduction}

Though difficult to define, aggression is ubiquitous in human societies and transcends age, race, and societal milieu. In children, differentiating between pathologic aggressive behavior and developmentally-bound aggression can be difficult. To this end, many children may exhibit aggression in the context of tantrums or angry outbursts. There may be problems in differentiating between this developmentally-bound aggression of a child and pathological pediatric aggression. ${ }^{1}$ Pathologic pediatric aggression may be more severe than developmentally-bound aggression, in terms of incidence, length, and amount of aggression. ${ }^{1}$

In the pediatric population, pathologic aggression can be physical or verbal and may be directed towards self or others. Physical aggression can be further characterized as impulsive, reactive, predatory, or premeditated. Impulsive aggression usually occurs in response to a stimulus, whereas predatory aggression is usually planned in advance of the act. ${ }^{2}$ Thus, pediatric aggression is a nonspecific symptom that transcends a number of psychiatric disorders. The diagnostic complexity of child and adolescent aggression further relates to the fact that multiple illnesses may involve aggression. Aggressive behaviors may be seen in attention-deficit or hyperactivity 
disorder (ADHD), posttraumatic stress disorder (PTSD), and oppositional defiant disorder. ${ }^{3}$ It can be challenging to determine the primary psychiatric diagnosis and what kind of predominant aggressive pattern (impulsive or premeditated) exists. This dilemma may complicate the treatment of the two different types of aggression as they may be approached in different ways. ${ }^{4}$

Treatment of pediatric aggression is often complicated by difficulties related to diagnostic issues, multiple medications used by clinicians, and the variety of psychological and environmental factors, which may directly affect the expression of aggression in youth. Psychopharmacologic treatment may require a long period, empiric trials of multiple medications until desired effects are attained. Thus, the main causes of the aggression need to be targeted and treated for the aggression to abate. ${ }^{5}$ A myriad of medications can be used to treat pediatric aggression, including antipsychotics, antidepressants, antiadrenergics, and mood stabilizers. Moreover, a number of nonpsychopharmacologic interventions, including different psychotherapies, are available for the treatment of pediatric aggression associated with a number of mental illnesses.

Aggressive behavior in children can result from a variety of experiences. Accumulating evidence from both clinical studies and investigations conducted in lower animals suggests that early life stress is a significant risk factor for the development of pathologic aggression..$^{6-10}$ Early life stress can take many forms including early social deprivation or exposure to trauma, abuse, or neglect. ${ }^{6}$ Many studies have found functional and structural differences in the brains of those exposed to maltreatment. ${ }^{11}$ Biological factors of pediatric aggression can be related to neuroendocrine abnormalities, genetics, and substance abuse. ${ }^{12}$ Moreover, deficits in social skills have also been linked to pediatric aggression. ${ }^{13}$ Children who are not able to adjust to a social environment may act out in an aggressive manner.

Although it is evident that pediatric aggression has many causes and contributing factors, a number of biological findings have been associated with pediatric aggression and will be reviewed in the context of selected aspects of neuroendocrine function and dysfunction.

\section{Neurochemical systems and pediatric aggression}

A constellation of neurochemical systems have been implicated in the physiology of aggression. Although herein we will focus primarily on the hypothalamic-pituitary-adrenal (HPA) axis, this system has a number of intimate relationships with other neuroendocrine systems, which are important for clinicians and neurobiologists to consider. In this review, the central monoaminergic systems (eg, norepinephrine and dopamine) and the serotonin system will be briefly reviewed with regard to their relationships with both aggression and the HPA axis.

The dopaminergic system consists of cell bodies that are primarily localized in the ventral tegmental area of the midbrain and the nucleus accumbens. These nuclei give rise to a number of tracts that project throughout various brain regions, which functionally subserve emotional regulation, motor command, cognitive processing, and neuroendocrine control. With regard to the issue of neuroendocrine control, the anterior pituitary, which ultimately modulates the release of the end products of the major hormones (the focus of this review), is coated with dopamine receptors highlighting the influence of the dopamine system on the HPA and hypothalamic-pituitary-gonadal (HPG) axes. In fact, the relationship between central nervous system dopamine release and elaborates of the HPA axis is complicated and likely reflects bidirectional influences and common stimuli. For example, both preclinical and clinical studies document cortisol-induced increases in central dopaminergic activity. ${ }^{14}$ With specific regard to impulsive aggression, a study of adults, which assessed cerebral blood flow using single photon emission computed tomography, suggests that regional blood flow may be increased in the nucleus accumbens, which itself directs important fibers to limbic regions; ${ }^{15}$ however, it remains unknown whether individuals without PTSD but with impulsive aggression would have similar increases in this region. Interestingly, from a neurochemical standpoint, cerebrospinal fluid sampling studies in adults have consistently linked high levels of the major dopamine metabolite, homovanillic acid, a finding consistent with high dopamine turnover, with higher levels of aggression in violent forensic samples. ${ }^{16}$ Moreover, the same has been observed in men convicted of murder. ${ }^{17}$ Similarly, levels of this compound are also abnormal in youth with aggression and comorbid ADHD. ${ }^{18}$ Indirect clinical evidence for the role of dopamine in the involvement of aggression includes the observation that patients, both youth and adults, who ingest cocaine (which increases postsynaptic effects of dopamine) become aggressive. ${ }^{19}$ In addition, drugs that block central dopamine receptors (eg, first and second generation antipsychotics) often have antiaggressive effects.

The catecholamine norepinephrine plays a critical role as one of the principal mediators of the mammalian response to stress. Thus, it is not surprising that it plays a central role in the modulation of aggression in both humans and lower animals. 
Central norepinephrine production occurs in the locus coeruleus, whose cell bodies project to a constellation of structures that are altered or implicated in the pathophysiology of aggression, including the prefrontal cortex, amygdala, hippocampus, hypothalamus, periaqueductal gray matter and, the thalamus. ${ }^{20}$ As with the dopaminergic system, the relationship between norepinephrine and other systems, which have been linked to aggression, is complicated. For example, administration of $\beta$-receptor agonists increases secretion of adrenocorticotropin-releasing hormone (ACTH), and in many conditions, the concentrations of cortisol and norepinephrine covary with one another. With regard to studies of aggression and its relationship with the concentrations of plasma norepinephrine, concentrations of this catecholamine have been found to be higher in healthy subjects with high-normal aggression than in those with low-normal aggressiveness ${ }^{21}$; however, not all studies of peripheral norepinephrine have observed these effects, ${ }^{22}$ which is likely related to the fact that concentrations of peripheral norepinephrine are poorly reflective of central norepinephrine concentrations. ${ }^{20,23}$ Further indirect support for the involvement of this system in aggression is provided by the clinically used postsynaptic $\beta$-receptor antagonists and presynaptic $\alpha_{2}$ receptor agonists to attenuate central noradrenergic tone, which are often used to decrease aggressive behaviors in youth with certain mental illnesses. ${ }^{24}$

Nearly, a quarter century of accumulating evidence has firmly established a link between the serotonergic system and the aggression ${ }^{16,18,25}$ and have been reviewed extensively in the literature. ${ }^{26}$ The serotonin system, whose cell bodies reside in the raphe nuclei of the brainstem, projects both rostrally and caudally and innervate a diverse group of brain regions including diencephalic and cortical structures, many of which have also been linked to aggression with functional imaging studies of aggressive adults and youth. ${ }^{27-29}$ Although an oversimplified summary neglects many nuances specific to individual history, individual attachment, individual psychopathology, etc, the serotonergic system is generally thought to be in a state of hypofunction in aggressive individuals. In a recent study of violent offenders, low cerebrospinal fluid concentrations of the major serotonin metabolite, and marker of serotonergic neurotransmission, 5-hydroxyindolacetic acid, were found to be high suggesting a link between "the outward-directed aggression of psychopathy to serotonergic hypofunctioning". ${ }^{16}$ Importantly, the serotonergic system operates in concert with many of the other systems described in this review and elsewhere, which have been implicated or could theoretically be involved in aggression, including the vigilance-promoting and arousal-regulating peptide orexin, ${ }^{30}$ the aggression modulating steroid hormone testosterone, ${ }^{31}$ thyroid function, ${ }^{32}$ and the covarying monoamine dopamine. ${ }^{23}$ Finally, from a pharmacologic standpoint, the distribution of brain 5- $\mathrm{HT}_{2 \mathrm{a}}$ receptors is markedly different in adults with histories of impulsive aggression as compared with those without, and agents, which act at these receptors (eg, second-generation antipsychotics), are often used clinically in treating symptoms of impulsive aggression. ${ }^{33}$

\section{The HPA axis and pediatric aggression}

Despite the significance of these monoaminergic systems, the HPA axis, which links the central nervous system with the peripheral response to stress,${ }^{34}$ has been the focus of many studies of pediatric aggression because it is one of the main regulators of stress in the body. ${ }^{35}$ The HPA axis instigates a cascade effect that eventually results in the production of cortisol. ${ }^{35}$ In times of stress and in certain psychiatric conditions, the hypothalamus releases the peptide hormone called corticotrophin-releasing hormone (CRH), which stimulates the pituitary to secrete ACTH (Figure 1A). In response to the $\mathrm{ACTH}$, the adrenal cortex releases glucocorticoids. Of these glucocorticoids, cortisol is perhaps the most studied and has intimate relationships with a diverse number of systems, inlcuding the immune system and the reproductive system, and even effects respiratory and cardiac functions. Moreover, this system is regulated through a series of negative feedback loops both at the level of the hypothalamus and pituitary wherein cortisol secretion inhibits release of CRH and $\mathrm{ACTH}$, respectively. ${ }^{34}$

Several studies have examined the function of HPA axis and the concentrations of cortisol in pediatric aggression. However, the results from the various studies have not been consistent. One study found that prepubertal children (aged 8-12 years, male and female) with disruptive behavior disorders had lower cortisol levels associated with a stress-inducing challenge. ${ }^{36}$ However, this study did not characterize the severity of aggression or type. The exact mechanisms involved with low levels of HPA axis activity are unknown. Therefore, it cannot be said how this would affect hormone concentrations in the body. McBurnett et $\mathrm{al}^{37}$ examined the relationship between plasma cortisol concentrations and aggression in 38 subjects (aged 7-12 years; male and female) and observed that low cortisol levels were associated with patterns of aggression and early onset of aggression in male children. ${ }^{37}$ Interestingly, a low variability with low cortisol levels over the long 
A.

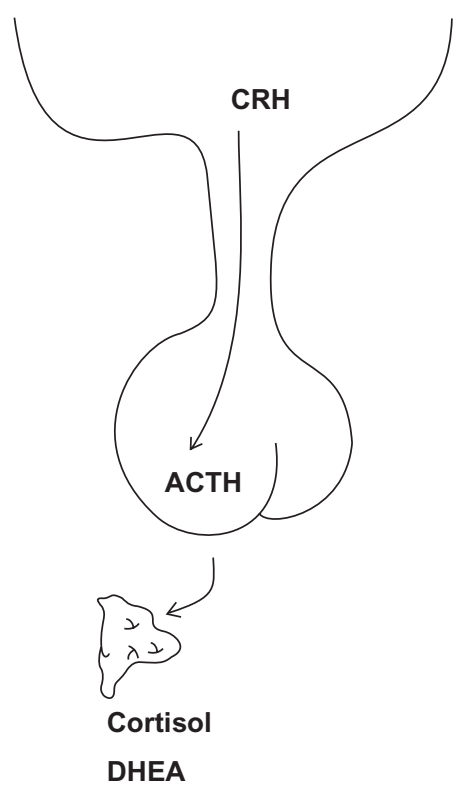

B.

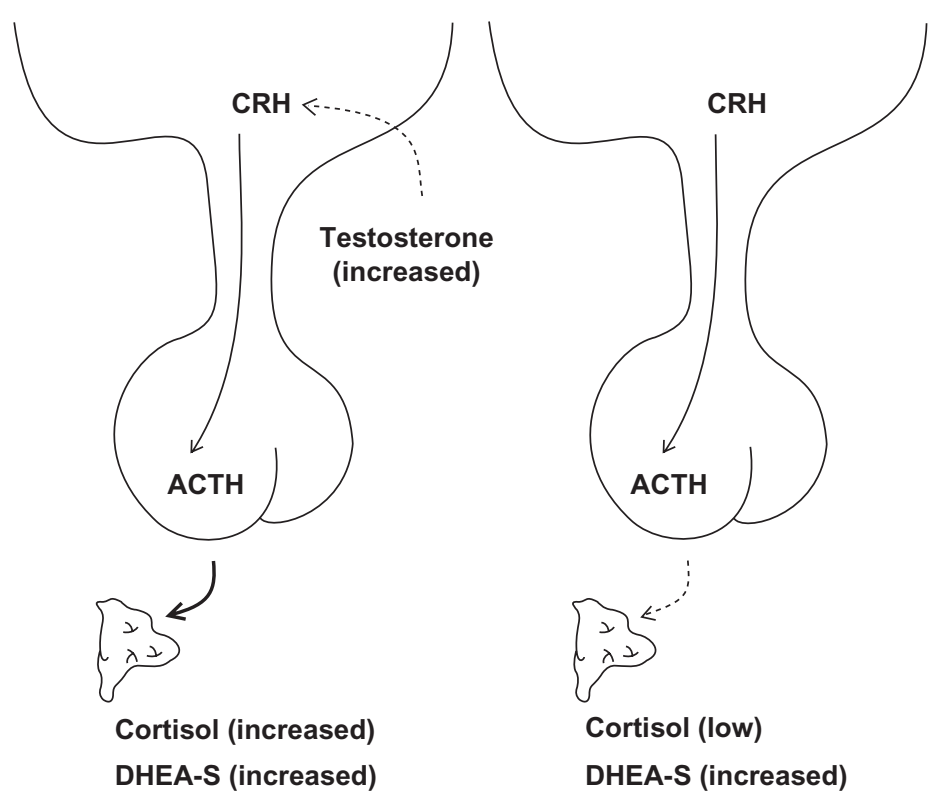

Figure I A) Neuroendocrine function among healthy children and adolescents; B) Children and adolescents with impulsive aggression; C) Children and adolescents with callous, unemotional traits. Solid arrows represent stimulation and dashed lines represent inhibitory pathways.

Abbreviations: $\mathrm{CRH}$, corticotrophin-releasing hormone; ACTH, adrenocorticotropin-releasing hormone; DHEA, dehydroepiandrosterone; DHEA-S, dehydroepiandrosterone sulfate.

term (collected at the second and fourth year of the study) was predictive of severe persistent pediatric aggression. ${ }^{37}$ In a subsequent study that focused on pediatric aggression rather than disruptive behavior disorders diminished postchallenge cortisol secretion corresponded to higher levels of aggression in 10 to 14-year-old children, but only in the presence of low sympathetic nervous system activity, as assessed by salivary $\alpha$-amylase concentrations, a surrogate of noradrenergic activity. ${ }^{38}$ This study provided evidence for the need to study more than one system at a time since biological systems are connected. Interestingly, in a study of males aged 10-12 years, it was noted that low cortisol levels correlated with aggressive behavior and impulsivity 5 years later (at ages $15-17$ years) ${ }^{39}$ However, to our knowledge, the potential predictive value of cortisol has not been assessed with regard to subsequent short-term aggression.

In an important study of the type of pediatric aggression and cortisol levels, Lopez-Duran et $\mathrm{al}^{40}$ evaluated cortisol reactivity in 73 6- to 7-year-old children and noted that subjects with patterns of reactive aggression had higher cortisol reactivity than the children with no aggression or proactive aggression. ${ }^{40}$ Moreover, in another study, Loney et $\mathrm{al}^{41}$ found that low basal cortisol levels were correlated with callous unemotional traits in male adolescents, but a similar relationship was not observed in female adolescents. ${ }^{41}$
This finding was consistent with their hypothesis that callous unemotional traits would be associated with low resting cortisol levels due to the low emotional reactivity. Serum cortisol concentrations can be considered biomarkers of "emotional reactivity", and thus, levels of cortisol may potentially help to predict the type of aggression and help with diagnosis and treatment. ${ }^{41}$

In contrast to the aforementioned studies, Sondeijker et al did not find a relationship between circulating cortisol concentrations and aggressive or disruptive behaviors ${ }^{42}$ However, the children in this study were from the general population, instead of high-risk children with more severe behavioral problems. Hence, it would be important to carefully consider the characteristics of the groups of children to be studied when measuring hormonal levels. In future pediatric studies, three groups including a low-risk clinical group, a high-risk clinical group, and a control nonclinical group would allow researchers to determine how cortisol levels differ between children with a range of risk for aggression (from none to high levels). The level of risk for potential pediatric aggression and violence in child psychiatry inpatient units could be measured using the brief rating of aggression by children and adolescents. ${ }^{43}$ In future neuroendocrine pediatric aggression studies, it is also important to differentiate between patterns of callous unemotional aggression and impulsive aggression. 
Given the above findings, it is important to consider the etiology of the HPA pathology and pediatric aggression. In response to certain types of early life stress, the HPA axis may become dysregulated. This HPA dysregulation may result in a vulnerability for the development of psychopathology and antisocial behavior. ${ }^{44}$ To this end, structural neuroanatomic differences in those exposed to maltreatment may be related to increased cortisol concentrations, which specifically alter the structure of glucocorticoid sensitive areas of the brain. ${ }^{45}$

The neurobiology of attachment is highly relevant for understanding hormones and pediatric aggression. Disorganized attachment, in which a child has no ability to organize a response to elicit care under stress, is a risk factor for the development of aggressive behavior in school-aged children. ${ }^{46}$ Several studies have also shown a correlation between cortisol levels and attachment pattern. A study investigating prenatal cortisol exposure found that increased amniotic fluid levels of cortisol negatively impacted infants' cognitive ability, but this effect only persisted if the infant-mother dyad developed an insecure attachment. ${ }^{47}$ Infants whose mothers had high-quality maternal behavior have more normal cortisol recovery in response to stress. ${ }^{48}$ Understanding the neurobiological mechanism of attachment-related pathology may help design treatments to abate HPA dysregulation. Accordingly, a recent study demonstrated that attachment-based psychotherapeutic interventions in children in foster care resulted in normalization of cortisol levels in response to social stressors. ${ }^{49}$

\section{The effects of sex hormones and their precursors on pediatric aggression}

Dehydroepiandrosterone (DHEA), a neurosteroid produced by the adrenal cortex and the brain, ${ }^{50,51}$ is a precursor to sex hormones, such as testosterone and estrogen. A more stable and sulfated form of this compound, dehydroepiandrosterone sulfate (DHEA-S), is commonly measured secondary to its inherent stability. Circulating DHEA levels increase quickly (around 7 years old in females and around 9 years old in males) and then decline later in life..$^{51}$

Not surprisingly, DHEA-S has been studied in child and adolescent psychiatry to understand its effect on aggressive behavior. In a study of 16 adolescents with conduct disorder, the circulating DHEA-S concentrations were measured in relation to observed aggression (as measured using the Overt Aggression Scales and the Child Behavior Checklist).
Higher DHEA-S levels were found in the adolescents with conduct disorder as compared with a healthy group of adolescents. ${ }^{51}$ Another study found that in male children (aged 8-12 years) with pathological aggression and conduct disorder, the DHEA-S levels were significantly higher than control subjects. Using ratings by parents and teachers, this study found that the high DHEA-S levels were associated with antisocial behaviors and aggression in these school-aged children. ${ }^{52}$ Similar results were found in a German study that compared DHEA-S levels in 28 boys aged 10-18 years with conduct disorder and 13 comparison subjects. ${ }^{53}$ The subjects with conduct disorder had high DHEA-S concentrations as compared with the comparison subjects.

Testosterone, an androgen that circulates throughout human blood and readily crosses the blood-brain barrier, is present in both males and females but is commonly known as the male sex hormone. ${ }^{54}$ Fluctuations of testosterone concentration may be associated with aggression and mood changes. ${ }^{55}$ Scerbo and Kolko ${ }^{56}$ evaluated salivary testosterone and cortisol concentrations in 40 children, aged 7-14 years (37 boys and three girls), with aggressive behaviors and observed an association between higher testosterone levels and aggressive behaviors. In addition, the higher cortisol concentrations were associated with internalizing behaviors. ${ }^{56}$ Similarly, in adolescent males, higher testosterone levels were associated with provoked verbal and physical aggression, a finding suggesting that reactive impulsive aggression is correlated with higher testosterone levels. ${ }^{54}$

Importantly, however, not all studies have observed differences in serum testosterone levels between aggressive and nonaggressive boys. ${ }^{57}$ In this study of 4 - to 10 -year olds, there was no evidence to suggest a relationship between testosterone levels and aggressive behaviors in prepubertal children. To our surprise, the relationship between aggressive behavior and testosterone or gonadal function remains to be developed and, thus, suggests a more limited potential for testosterone as a biomarker for pediatric aggression.

\section{Future directions}

The existing data suggest that hormonal levels (eg, in saliva, serum, plasma, urine, etc) could be of potential clinical utility in that concentrations might assist in clarifying the subtype of pediatric aggression, which directly relates to subtype-specific psychopharmacologic or psychotherapeutic treatments. Thus, given the evidence that certain hormonal concentrations are associated with pediatric aggression and may be specific to the type of pediatric aggression, it is not 
unreasonable to suppose that salivary hormone assays can help in identifying pediatric patients that would respond best to certain treatments.

\section{Disclosure}

The authors report no conflicts of interest in this work.

\section{References}

1. Jensen PS, Youngstrom EA, Steiner H, et al. Consensus report on impulsive aggression as a symptom across diagnostic categories in child psychiatry: implications for medication studies. J Am Acad Child Adolesc Psychiatry. 2007;46:309-322.

2. Stanford MS, Houston RJ, Mathias CW, Villemarette-Pittman NR, Helfritz LE, Conklin SM. Characterizing aggressive behavior. Assessment. 2003;10:183-190.

3. Pappadopulos E, Woolston S, Chait A, Perkins M, Connor DF, Jensen PS. Pharmacotherapy of aggression in children and adolescents: efficacy and effect size. J Can Acad Child Adolesc Psychiatry. 2006;15:27-39.

4. Weinshenker N, Siegel A. Bimodal classification of aggression: affective defense and predatory attack. Aggress Violent Behav. 2002;7:237-250.

5. Sugden S, Kile S, Hendren R. Neurodevelopmental pathways to aggression: a model to understand and target treatment in youth. J Neuropsychiatry Clin Neurosci. 2006;18:302-317.

6. Veenema AH. Early life stress, the development of aggression and neuroendocrine and neurobiological correlates: what can we learn from animal models? Front Neuroendocrinol. 2009;30:497-518.

7. Lewis DO. From abuse to violence: psychophysiological consequences of maltreatment. J Am Acad Child Adolesc Psychiatry. 1992;31:383-391.

8. Seifert J. Childhood trauma: its relationship to behavioral and psychiatric disorders. Forensic Examiner. 2003;12:27-33.

9. Maas C, Herrenkohl TI, Sousa C. Review of research on child maltreatment and violence in youth. Trauma Violence Abuse. 2008;9:56-67.

10. Stouthamer-Loeber M, Loeber R, Homish D, Wei E. Maltreatment of boys and the development of disruptive and delinquent behavior. Dev Psychopathol. 2001;13:941-955.

11. McCrory E, de Brito SA, Viding E. Research review: the neurobiology and genetics of maltreatment and adversity. J Child Psychol Psychiatry. Epub 2010 Jun 7.

12. Berkowitz L. Aggression: Its Causes, Consequences, and Control. New York, NY: McGraw-Hill; 1993.

13. Kaukiainen A, Bjorkqvist K, Lagerspetz K. The relationships between social intelligence, empathy, and three types of aggression. Aggr Behav. 1999;25:81-89.

14. Oswald LM, Wong DF, McCaul M, et al. Relationships among ventral striatal dopamine release, cortisol secretion, and subjective responses to amphetamine. Neuropsychopharmacology. 2005;30:821-832.

15. Pavic L, Gregurek R, Petrovic R, et al. Alterations in brain activation in posttraumatic stress disorder patients with severe hyperarousal symptoms and impulsive aggressiveness. Eur Arch Psychiatry Clin Neurosci. $2003 ; 253: 80-83$.

16. Soderstrom H, Blennow K, Manhem A, Forsman A. CSF studies in violent offenders. I. 5-HIAA as a negative and HVA as a positive predictor of psychopathy. J Neural Transm. 2001;108:869-878.

17. Lidberg L, Tuck JR, Asberg M, Scalia-Tomba GP, Bertilsson L. Homicide, suicide and CSF 5-HIAA. Acta Psychiatr Scand. 1985;71:230-236.

18. Castellanos FX, Elia J, Kruesi MJ, et al. Cerebrospinal fluid monoamine metabolites in boys with attention-deficit hyperactivity disorder. Psychiatry Res. 1994;52:305-316.

19. Mathias S, Lubman DI, Hides L. Substance-induced psychosis: a diagnostic conundrum. J Clin Psychiatry. 2008;69:358-367.

20. Strawn JR, Geracioti TD Jr. Noradrenergic dysfunction and the psychopharmacology of posttraumatic stress disorder. Depress Anxiety. 2008;25:260-271.
21. Gerra G, Zaimovic A, Avanzini P, et al. Neurotransmitter-neuroendocrine responses to experimentally induced aggression in humans: influence of personality variable. Psychiatry Res. 1997;66:33-43.

22. Gerra G, Avanzini P, Zaimovic A, et al. Neurotransmitter and endocrine modulation of aggressive behavior and its components in normal humans. Behav Brain Res. 1996;81:19-24.

23. Geracioti TD Jr, Keck PE Jr, Ekhator NN, et al. Continuous covariability of dopamine and serotonin metabolites in human cerebrospinal fluid. Biol Psychiatry. 1998;44:228-233.

24. Armenteros JL, Lewis JE. Citalopram treatment for impulsive aggression in children and adolescents: an open pilot study. J Am Acad Child Adolesc Psychiatry. 2002;41:522-529.

25. Brown GL, Ebert MH, Goyer PF, et al. Aggression, suicide, and serotonin: relationships to CSF amine metabolites. Am J Psychiatry. 1982; 139:741-746.

26. Popova NK. From genes to aggressive behavior: the role of serotonergic system. Bioessays. 2006;28:495-503.

27. Bufkin JL, Luttrell VR. Neuroimaging studies of aggressive and violent behavior: current findings and implications for criminology and criminal justice. Trauma Violence Abuse. 2005;6:176-191.

28. de Brito S, Mechelli A, Wilke M, et al. Size matters: increased grey matter in boys with conduct problems and callous-unemotional traits. Brain. 2009;132:843-852.

29. Decety J, Michalska KJ, Akitsuki Y, Lahey BB. Atypical empathic responses in adolescents with aggressive conduct disorder: a functional MRI investigation. Biol Psychol. 2009;80:203-211.

30. Strawn JR, Pyne-Geithman GJ, Ekhator NN, et al. Low cerebrospinal fluid and plasma orexin-A (hypocretin-1) concentrations in combatrelated posttraumatic stress disorder. Psychoneuroendocrinology. 2010; 35:1001-1007.

31. Kuepper Y, Alexander N, Osinsky R, et al. Aggression - interactions of serotonin and testosterone in healthy men and women. Behav Brain Res. 2010;206:93-100.

32. Strawn JR, Ekhator NN, D'Souza BB, Geracioti TD Jr. Pituitary-thyroid state correlates with central dopaminergic and serotonergic activity in healthy humans. Neuropsychobiology. 2004;49:84-87.

33. Soloff P, Price J, Mason N, Becker C, Meltzer C. Gender, personality, and serotonin-2A receptor binding in healthy subjects. Psychiatry Res. 2010;181:77-84.

34. Kudielka BM, Kirschbaum C. Sex differences in HPA axis responses to stress: a review. Biol Psychol. 2005;69:113-132.

35. Hawes DJ, Brennan J, Dadds MR. Cortisol, callous-unemotional traits, and pathways to antisocial behavior. Curr Opin Psychiatry. 2009;22: $357-362$.

36. Goozen SV, Mattthys W, Cohen-Kettenis P, Peggy T, Buitelaar J, Engeland HV. Hypothalamic-pituitary-adrenal axis and autonomic nervous system activity in disruptive children and matched controls. J Am Acad Child Adolesc Psychiatry. 2000;39:1438-1445.

37. McBurnett K, Lahey BB, Rathouz PJ, Loeber R. Low salivary cortisol and persistent aggression in boys referred for disruptive behavior. Arch Gen Psychiatry. 2000;57:38-43.

38. Gordis EB, Granger DA, Susman EJ, Trickett PK. Asymmetry between salivary cortisol and alpha-amylase reactivity to stress: relation to aggressive behavior in adolescents. Psychoneuroendocrinology. 2006;31:976-987.

39. Shoal GD, Giancola PR, Kirillova GP. Salivary cortisol, personality, and aggressive behavior in adolescent boys: a 5-year longitudinal study. J Am Acad Child Adolesc Psychiatry. 2003;42:1101-1107.

40. Lopez-Duran NL, Olson SL, Hajal NJ, Felt BT, Vazquez DM. Hypothalamic pituitary adrenal axis functioning in reactive and proactive aggression in children. J Abnorm Child Psychol. 2009;37:169-182.

41. Loney J, Carlson GA, Salisbury H, Volpe RJ. Validation of three dimensions of childhood psychopathology in young clinic-referred boys. J Atten Disord. 2005;8:169-181.

42. Sondeijker FE, Ferdinand RF, Oldehinkel AJ, et al. Disruptive behaviors and HPA-axis activity in young adolescent boys and girls from the general population. J Psychiatr Res. 2007;41:570-578. 
43. Barzman D, Brackenberry L, Sonnier L, et al. Brief rating of aggression by children and adolescents (BRACHA): development of a tool to assess risk of inpatients' aggressive behavior. J Am Acad Psychiatry Law. In press 2011.

44. Goozen SV, Fairchild G, Snoek H, Harold G. The evidence for a neurobiological model of childhood antisocial behavior. Psychol Bull. 2007;133:149-182.

45. Bellis MD, Hooper S, Woolley D, Shenk C. Demographic, maltreatment, and neurobiological correlates of PTSD symptoms in children and adolescents. J Pediatr Psychol. 2010;35:570-577.

46. Lyons-Ruth K. Attachment relationships among children with aggressive behavior problems: the role of disorganized early attachment patterns. J Consult Clin Psychol. 1996;64:64-73.

47. Bergman K, Sarkar P, Glover V, O'Connor TG. Maternal prenatal cortisol and infant cognitive development: moderation by infant-mother attachment. Biol Psychiatry. 2010;67:1026-1032.

48. Albers EM, Riksen-Walraven JM, Sweep FC, de Weerth C. Maternal behavior predicts infant cortisol recovery from a mild everyday stressor. J Child Psychol Psychiatry. 2008;49:97-103.

49. Dozier M, Peloso E, Lewis E, Laurenceau JP, Levine S. Effects of an attachment-based intervention on the cortisol production of infants and toddlers in foster care. Dev Psychopathol. 2008;20:845-859.

50. Baulieu EE, Robel P. Dehydroepiandrosterone (DHEA) and dehydroepiandrosterone sulfate (DHEAS) as neuroactive neurosteroids. Proc Natl Acad Sci U SA. 1998;95:4089-4091.
51. Golubchik P, Mozes T, Maayan R, Weizman A. Neurosteroid blood levels in delinquent adolescent boys with conduct disorder. Eur Neuropsychopharmacol. 2009;19:49-52.

52. van Goozen SH, Matthys W, Cohen-Kettenis PT, Thijssen JH, van Engeland $\mathrm{H}$. Adrenal androgens and aggression in conduct disorder prepubertal boys and normal controls. Biol Psychiatry. 1998;43: $156-158$.

53. Dmitrieva TN, Oades RD, Hauffa BP, Eggers C. Dehydroepiandrosterone sulphate and corticotropin levels are high in young male patients with conduct disorder: comparisons for growth factors, thyroid and gonadal hormones. Neuropsychobiology. 2001;43:134-140.

54. Olweus D, Mattsson A, Schalling D, Low H. Circulating testosterone levels and aggression in adolescent males: a causal analysis. Psychosom Med. 1988;50:261-272.

55. van Wingen G, Mattern C, Jan Verkes R, Buitelaar J, Fernandez G. Testosterone reduces amygdala-orbitofrontal cortex coupling. Psychoneuroendocrinology. 2010;35:105-113.

56. Scerbo AS, Kolko DJ. Salivary testosterone and cortisol in disruptive children: relationship to aggressive, hyperactive, and internalizing behaviors. J Am Acad Child Adolesc Psychiatry. 1994;33: 1174-1184.

57. Constantino JN, Grosz D, Saenger P, Chandler DW, Nandi R, Earls FJ. Testosterone and aggression in children. J Am Acad Child Adolesc Psychiatry. 1993;32:1217-1222.
Neuropsychiatric Disease and Treatment

\section{Publish your work in this journal}

Neuropsychiatric Disease and Treatment is an international, peerreviewed journal of clinical therapeutics and pharmacology focusing on concise rapid reporting of clinical or pre-clinical studies on a range of neuropsychiatric and neurological disorders. This journal is indexed on PubMed Central, the 'PsycINFO' database and CAS, and is the official

\section{Dovepress}

journal of The International Neuropsychiatric Association (INA). The manuscript management system is completely online and includes a very quick and fair peer-review system, which is all easy to use. Visit http://www.dovepress.com/testimonials.php to read real quotes from published authors. 